\title{
Perventricular device closure of muscular ventricular septal defects on beating hearts: Initial experience in eight children
}

\author{
Changping Gan, MS, ${ }^{\mathrm{a}}$ Ke Lin, MD, ${ }^{\mathrm{a}}$ Qi An, MD, ${ }^{\mathrm{a}}$ Hong Tang, MD, ${ }^{\mathrm{b}}$ Haibo Song, MD, ${ }^{\mathrm{c}}$ Raphael C. Lui, MD, FRCSC, FACS, ${ }^{\mathrm{a}}$ \\ Kaiyu Tao, MS, ${ }^{a}$ Zhongyun Zhuang, MD, ${ }^{a}$ and Yingkang Shi, MD $^{\mathrm{a}}$
}

\begin{abstract}
Objective: The conventional surgical repair and transcatheter closure of muscular ventricular septal defects are known to have undesirable limitations. This communication describes the short-term results of perventricular device closure of muscular ventricular septal defects with the heart beating in 8 children with 15 muscular ventricular septal defects, with or without other congenital malformations.
\end{abstract}

\begin{abstract}
Methods: A subxiphoid minimally invasive incision was used in 3 children with isolated muscular ventricular septal defects whereas standard full median sternotomies were used in the other 5 children who required subsequent correction of coexisting malformations. Under the continuous guidance of transesophageal echocardiography, the free wall of the right ventricle was punctured, and a guidewire was introduced into the left ventricle through the defect. A delivery sheath was advanced over the wire and through the defect into the left ventricle. The device was released.
\end{abstract}

Results: A total of 14 muscular ventricular septal defects were successfully closed perventricularly without cardiopulmonary bypass. There was no mortality perioperatively or during the entire follow-up period. At 6-month follow-up, there was no detectable residual shunt, arrhythmia, or new mitral or tricuspid insufficiency. Other than 5 children with the coexisting malformations, none of the other children required any blood or blood products. The average hospital stay was $7.9 \pm 2.2$ days (range, $5-11$ days).

Conclusion: Perventricular device closure of muscular ventricular septal defects with or without coexisting congenital malformations appeared to be safe and efficacious. The outcomes of short-term follow-up are acceptable.

Despite the fact that the results of conventional surgical repair of muscular ventricular septal defects (MVSDs) with cardiopulmonary bypass (CPB) in terms of hospital mortality have been steadily improving during recent years, ${ }^{1}$ the persistent relatively high risk of postoperative residual shunt continues to be of concern. ${ }^{2,3}$ During the surgical repair of MVSDs with CPB and the heart arrested, one of the commonly encountered technical difficulties, despite extensive dissection of the trabeculae, continues to be the difficulty in obtaining adequate exposure and thus visualization of the MVSDs. In 2000 , clinical experience with percutaneous transcatheter closure of single MVSDs with the Amplatzer occluder (AGA Medical Corporation, Plymouth, Minn) was first described. ${ }^{4}$ However, this approach has limited applicability in young children owing to the disparity between the sizes of the sheaths and the patients' access vessels. Several years later, another report of 69 patients treated with this approach docu-

\footnotetext{
From the Departments of Thoracic and Cardiovascular Surgery, ${ }^{\mathrm{a}}$ Echocardiography, and Anesthesiology, ${ }^{\mathrm{c}}$ West China Hospital, Sichuan University, Chengdu, Sichuan, People's Republic of China.

Dr Changping Gan and Dr Ke Lin contributed equally to this article.

Supported in part by a grant (2006BAI01A08) from The Ministry of Science and Technology of The People's Republic of China.

Received for publication May 22, 2008; revisions received Aug 18, 2008; accepted for publication Sept 1, 2008.

Address for reprints: Qi An, MD, Department of Thoracic and Cardiovascular Surgery, West China Hospital, Sichuan University, Chengdu, Sichuan, People's Republic of China, 610041 (E-mail: anqi8890@163.com).

J Thorac Cardiovasc Surg 2009;137:929-33

$0022-5223 / \$ 36.00$

Copyright (c) 2009 by The American Association for Thoracic Surgery

doi:10.1016/j.jtcvs.2008.09.010
}

mented a mortality of $2.9 \%$ and a major complication rate of $11 \%{ }^{5}$ Perventricular device closure (PVDC) of MVSDs on the beating heart was first described in 1998 as another treatment option, ${ }^{6}$ and this technique was refined in 2003 after a consecutive series of 6 patients with encouraging results. ${ }^{7}$ This approach appears especially appealing for children with multiple MVSDs or other associated congenital heart diseases (CHDs) who may otherwise require a prolonged $\mathrm{CPB}$ time with the subsequent complications. More recently, early clinical experience with PVDC of nonmuscular VSDs have been reported by us ${ }^{8}$ and another center. ${ }^{9}$ We herein describe our initial experience with PVDC of MVSDs in 8 children with either isolated singular MVSD or multiple MVSDs, with or without other associated CHDs.

\section{PATIENTS AND METHODS \\ Patients}

Between May and September of 2007, 8 children were admitted with the diagnosis of either singular or multiple MVSDs that were of hemodynamic significance. Five children also had associated CHDs. There were 4 boys and 4 girls, with a mean age of $2.5 \pm 3.6$ years (range, $0.5-11.0$ years) and a mean body weight of $10.9 \pm 7.6 \mathrm{~kg}$ (range, $5.5-27.5 \mathrm{~kg}$ ). The use of PVDC to treat MVSDs was approved by the hospital ethics committee and individual consents were obtained from both parents of all the children after all the pros and cons of the procedure were explained. Immediately before skin incision and under general anesthesia, all the children underwent thorough transesophageal echocardiograms (TEEs) by the same echocardiographer to confirm the preoperative transthoracic echocardiographic findings, and the following data were recorded: (1) the dimension(s) of all the MVSDs and the spatial relationship between the multiple MVSDs; (2) the details, if any, of the associated CHDs. If the posterior rim of a defect 


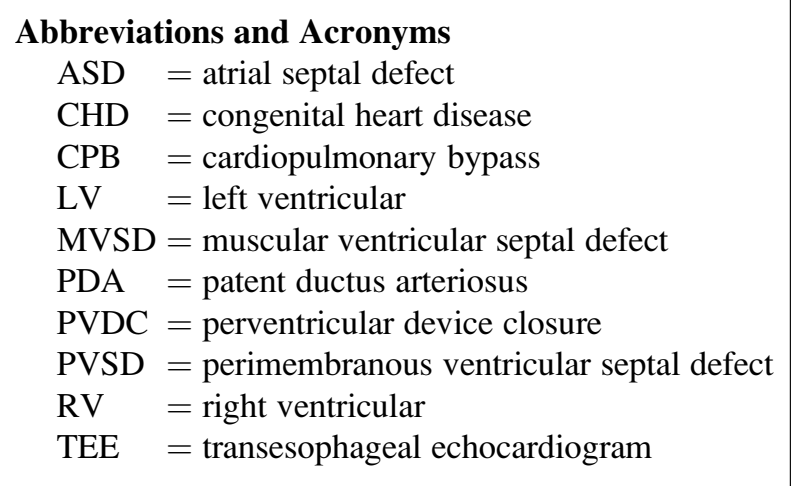

was too close to the tricuspid annulus or the anterior rim of a large anterior defect was absent, we would not conduct a device closure. Three $(37.5 \%)$ children had a singular MVSD and 1 of them had associated CHDs. All the other $5(62.5 \%)$ children had multiple MVSDs with associated CHDs. The mean diameter of the MVSDs was $4.9 \pm 2.4 \mathrm{~mm}$ (range, 2.0 $10.0 \mathrm{~mm}$ ). None of the children had cardiac arrhythmia before surgery. Patient demographics, the dimensions and locations of the MVSDs, and the associated CHDs are given in Table 1.

\section{The Devices}

There are two kinds of occluder (Shanghai Shape Memory Alloy Corporation, Shanghai, China): one is a muscular occluder and the other is a patent ductus arteriosus (PDA) occluder (Figure 1). The basic characteristics of the muscular occluder have been described before, ${ }^{10}$ but the flange of our device is $3 \mathrm{~mm}$ wider than the waist on the left ventricular (LV) side and 2 $\mathrm{mm}$ wider than the waist on the right ventricular (RV) side. The PDA occluder is similar to that in another study, ${ }^{11}$ and each occluder is designated by the diameters of both the LV and RV waist.

\section{Perventricular Technique}

In the child with isolated MVSDs and no CPB anticipated, a subxiphoid 3- to 4-cm skin incision was made followed by a lower partial sternotomy. The pericardium was partially and longitudinally incised and suspended for adequate exposure. In the other children with associated CHDs, conventional full median sternotomies were used. With the heart beating and under continuous TEE guidance, the RV free wall was gently depressed with the surgeon's index finger. The depression on the RV free wall was easily visualized by TEE. By changing the location of the depression, we could determine a point on the $\mathrm{RV}$ free wall that was nearest to the defect to be occluded and yet preserve adequate distance and space to allow manipulation of the guidewire, sheath, and release of the device. The following technique was similar to that in another research report. ${ }^{7}$ If a PDA occluder was used, the LV disc was similarly released first, followed by the release of the waist. The appropriate device size was chosen to be 1 to $2 \mathrm{~mm}$ larger than the defect size. If a single device was selected to close 2 nearby defects simultaneously, the diameter of its left disc should just cover the 2 VSDs. At this point, the echocardiographer would carefully look for any residual shunt or new mitral or tricuspid regurgitation. If none was found, the device was released. If the child had associated CHDs that needed open cardiac repair, CPB was established in the usual fashion and the CHDs were closed accordingly. All the children received broad-spectrum second-generation cephalosporin for 3 days. Aspirin $(3 \mathrm{mg} / \mathrm{kg}$ ) was started on postoperative day 2 and continued for 6 months.

\section{Follow-up}

At discharge and 6-month follow-up, all the children underwent transthoracic echocardiographic examination by the same echocardiographer.
Specific attention was paid to look for any residual shunt and new mitral and tricuspid regurgitation. Twelve-lead electrocardiograms were also obtained at the same time to detect any arrhythmia.

\section{RESULTS}

Fourteen (93\%) of 15 MVSDs were successfully closed without CPB. Eleven MVSDs were closed by muscular occluders and 3 MVSDs were closed by PDA occluders.

\section{Singular MVSD}

Three children with singular MVSD successfully underwent PVDC with $8-\mathrm{mm}, 10-\mathrm{mm}$, and $10-\mathrm{mm}$ devices for their 7-mm, 8-mm, and 8-mm defects, respectively. There was no detectable residual shunt or any new mitral or tricuspid regurgitation by TEE after the releases of the devices. The child with associated CHDs (patient 1, Table 1) also underwent uneventful repair of her CHDs with CPB.

\section{Multiple MVSDs}

In the child with a 10-mm anterior MVSD and a 6-mm apical MVSD (patient 4, Table 1), we closed the anterior defect with a $12-\mathrm{mm}$ device uneventfully. We then used another RV free wall puncture site to establish a second pathway closer to the apex to close the apical MVSD (Figure 2). Since we anticipated that the RV apex would not have enough space to accommodate the regular occluder, we elected instead to use an 8/6-mm PDA occluder, which did not have an RV disc. The associated secundum type 6-mm atrial septal defect (ASD) was successfully closed with an 8-mm ASD occluder (Shanghai Shape Memory Alloy Corporation) via a right atrial puncture site (Figure 3). Another child (patient 5, Table 1) had 2 apical MVSDs, a large PDA, and a perimembranous VSD (PVSD). We attempted unsuccessfully to use the regular MVSD occluders to close these 2 apical MVSDs owing to the limited space at the apex, making opening the RV disc of the regular occluder impossible. We therefore switched to using two 8/6-mm and 6/4-mm PDA occluders to successfully close the 6-mm and 4-mm apical MVSDs. Immediate TEE examination did not detect any residual shunt. CPB was then established and the large PDA was ligated before cardioplegic arrest and repair of the PVSD.

In the child with 2 relatively small MVSDs that were only 3-mm apart, as well as a nonrestrictive PVSD (patient 6, Table 1), we closed the 4-mm posterior MVSD with a 6-mm occluder relatively easily and immediate TEE examination did not show any residual shunt. The nearby $2-\mathrm{mm}$ MVSD was also reduced to a $0.5-\mathrm{mm}$ defect. Owing to the small size of this defect and its close proximity to the occluder of the first defect, we were unable to pass the guidewire into the LV cavity after multiple attempts. We then accurately established the spatial relationship between this small defect and the first occluder before establishing CPB and closing this defect with pledget-supported 4-0 Prolene 
TABLE 1. Characteristics of the patients, MVSDs, and associated CHDs

\begin{tabular}{|c|c|c|c|c|c|c|c|c|}
\hline \multirow{2}{*}{$\begin{array}{c}\text { Patient } \\
\text { No. } \\
\end{array}$} & \multirow{2}{*}{$\begin{array}{c}\text { Gender } \\
(\mathbf{M} / \mathbf{F})\end{array}$} & \multirow[b]{2}{*}{ Age (y) } & \multirow{2}{*}{$\begin{array}{c}\text { Weight } \\
(\mathrm{kg})\end{array}$} & \multicolumn{4}{|c|}{ Diameter (mm)/location of MVSDs (Size [mm]/type of device) } & \multirow[b]{2}{*}{ Associated CHDs } \\
\hline & & & & MVSD1 & MVSD2 & MVSD3 & MVSD4 & \\
\hline 1 & $\mathrm{~F}$ & $8 / 12$ & 8 & 7/middle (8/MO) & - & - & - & $\begin{array}{l}\text { PAPVC, ASD (posterior, } \\
12 \mathrm{~mm} \text { ), PVSD (12 } \\
\mathrm{mm} \text { ), TR (moderate) }\end{array}$ \\
\hline 2 & M & $6 / 12$ & 5.5 & 8/middle (10/MO) & - & - & - & - \\
\hline 3 & M & $10 / 12$ & 8 & 8/middle (10/MO) & - & - & - & - \\
\hline 4 & $\mathrm{~F}$ & $9 / 12$ & 6 & 10/anterior (12/MO) & $\begin{array}{l}\text { 6/apical } \\
\quad(8-6 / \mathrm{PDAO})\end{array}$ & - & 一 & $\begin{array}{l}\text { ASD (ostium secundum, } \\
\quad 6 \mathrm{~mm} \text { ) }\end{array}$ \\
\hline 5 & $\mathrm{~F}$ & $19 / 12$ & 9.5 & 6/apical (8-6/ PDAO) & $\begin{array}{l}\text { 4/apical } \\
\quad(6-4 / \mathrm{PDAO})\end{array}$ & - & - & $\begin{array}{l}\text { PDA }(10 \times 8 \mathrm{~mm}), \text { PVSD } \\
\quad(15 \mathrm{~mm})\end{array}$ \\
\hline 6 & M & 11 & 27.5 & 4/posterior (6/MO) & 2/posterior & - & 一 & PVSD (25 mm), TR (mild) \\
\hline 7 & M & 4 & 17 & 3/middle (6/MO) & 3/middle (6/MO) & - & - & - \\
\hline 8 & $\mathrm{~F}$ & $9 / 12$ & 6 & $3.5 /$ anterior $(7 / \mathrm{MO})$ & 3.5/anterior (7/MO) & $\begin{array}{l}\text { 3/middle } \\
(5 / \mathrm{MO}) \\
\end{array}$ & $\begin{array}{r}3 / \text { posterior } \\
(5 / \mathrm{MO}) \\
\end{array}$ & $\begin{array}{l}\text { ASD (ostium secundum, } \\
12 \mathrm{~mm} \text { ) }\end{array}$ \\
\hline
\end{tabular}

$A S D$, Atrial septal defect; $C H D$ s, congenital heart diseases; $F$, female; $M$, male; $M O$, muscular occluder; $M V S D$, muscular ventricular septal defect; $P A P V C$, partial anomalous pulmonary venous connection; $P D A$, patent ductus arteriosus; $P D A O$, patent ductus arteriosus occluder; $P V S D$, perimembranous ventricular septal defect; $T R$, tricuspid regurgitation.

polypropylene suture (Ethicon, Inc, Somerville, NJ) through the tricuspid valve. The coexisting PVSD was closed in the usual fashion with a patch.

In another child (patient 7, Table 1) with two 3-mm large MVSDs that were 3-mm apart, we closed the defects with a single 6-mm occluder. The last girl (patient 8, Table 1) had 4 MVSDs and an ASD. We closed the 2 nearby anterior MVSDs with a single occluder and closed the middle and posterior MVSDs with two 5-mm occluders. Her ASD was also closed peratrially with a 12-mm ASD occluder

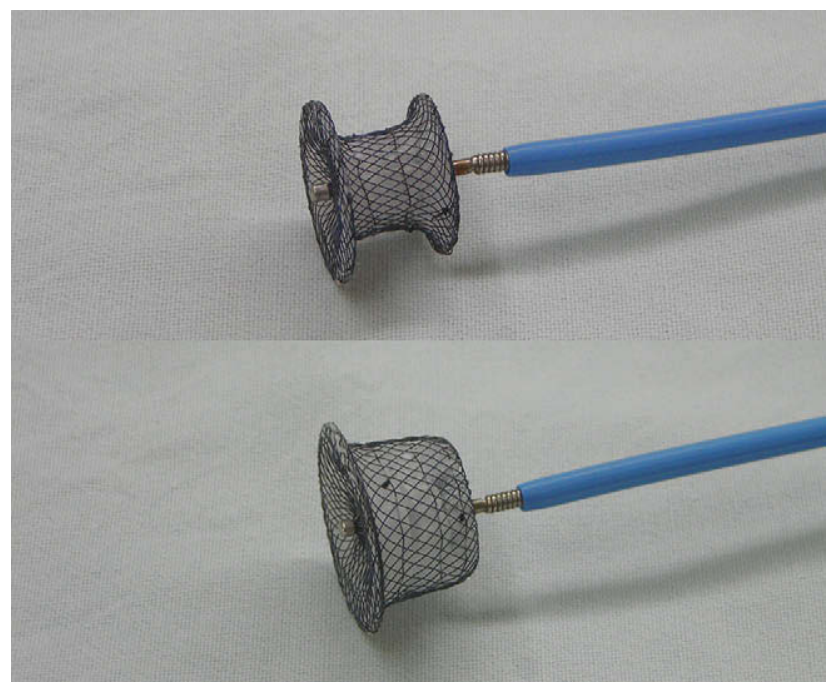

FIGURE 1. Top, The muscular occluder with the flange that is $3 \mathrm{~mm}$ wider than the waist on the left ventricular side and $2 \mathrm{~mm}$ wider than the waist on the right ventricular side. Bottom, The patent ductus arteriosus occluder with a 5-mm-tall isosceles trapezoid sagittal section and its left ventricular flange, which is $2 \mathrm{~mm}$ wider than the waist on the left ventricular side.
(Shanghai Shape Memory Alloy Corporation). TEE showed all 6 MVSDs were closed successfully and no residual shunt was detected.

At discharge and 6-month follow-up, there was no detectable residual shunt or any closure-related new mitral or tricuspid regurgitation or exacerbation of any pre-existing regurgitation. All the occluders appeared to be in good positions, and no arrhythmia was noticed. There was no mortality during the hospital stay or during the follow-up period. Three children who required CPB to repair the associated CHDs and 2 children who received multiple devices needed blood transfusion; the other 3 children did not require any blood or blood product transfusion. The average hospital stay was $7.9 \pm 2.2$ days (range, $5-11$ days).

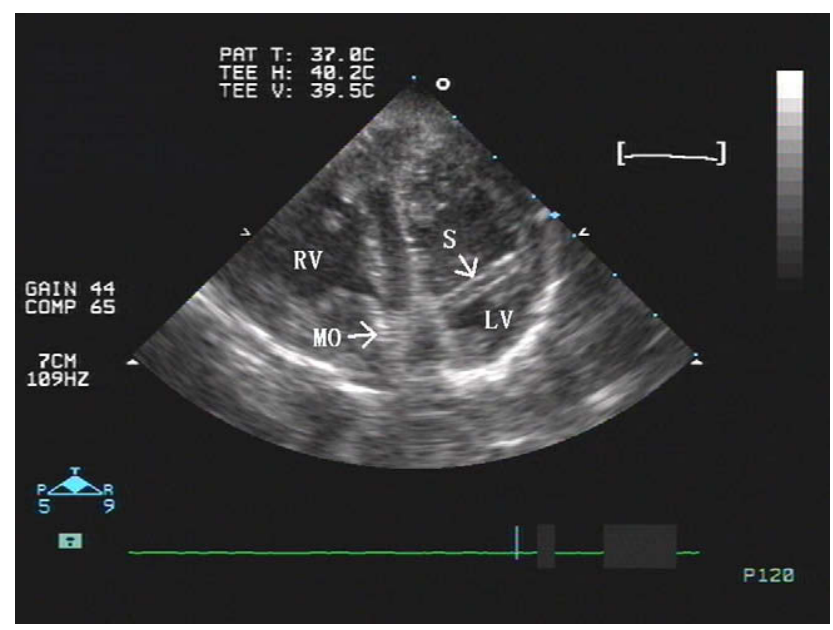

FIGURE 2. Another sheath was established through the apical defect after an anterior defect had been closed. $L V$, Left ventricle; $M O$, muscular occluder; $R V$, right ventricle; $S$, sheath. 


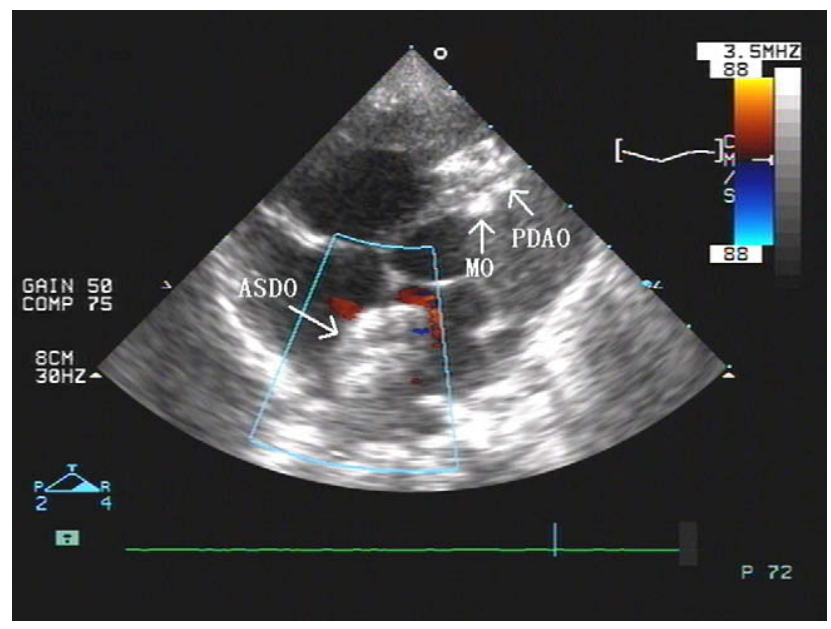

FIGURE 3. Three occluders were shown in one section, and the Doppler test showed no residual shunt between the two atria. ASDO, Atrial septal defect occluder; $M O$, muscular occluder; $P D A O$, patent ductus arteriosus occluder.

\section{DISCUSSION}

MVSD can be singular or multiple. At its extreme form, it can present as "Swiss cheese", type. ${ }^{12}$ When MVSDs become hemodynamically significant, especially when they are associated with other CHDs, early intervention is indicated. Owing to the unique locations of some of the MVSDs, especially those in the apical or anterior region of the ventricular septum, direct surgical repair with CPB and cardioplegic arrest can present significant difficulties. A right ventriculotomy will impair the long-term $\mathrm{RV}$ function and increase the likelihood of arrhythmia, ${ }^{13}$ but it can never guarantee a good exposure. Once inside the RV, the extensive trabeculation of the RV cavity makes either direct suture or patch closure technically challenging and more prone to result in residual shunt. Recent reports from a highly experienced center also attested to the challenging nature of surgical repair of MVSDs. ${ }^{14,15}$ The advent of the transcatheter approach provided a minimally invasive option for this disease process. However, this approach has limited applicability in young children owing to the disparity between the sizes of the sheaths and the devices required and the access vessels. ${ }^{5,16}$ On the contrary, PVDC of VSDs is almost not affected by the patient's age, body weight, or dimensions of the VSDs. In this study, we successfully closed an 8-mm MVSD in a 6-month-old boy who weighed only $5.5 \mathrm{~kg}$ and might have presented an overwhelming technical challenge to the transcatheter approach, let alone the prolonged radiation exposure with all its deleterious long-term effects. PVDC, on the other hand, uses strictly TEE for intraoperative control and thus avoids all the radiation. Compared with the conventional repair with CPB, PVDC with TEE control provides immediate and real-time assessment of the effects of the devices on valve functions, the presence of any residual shunt, and, if necessary, timely corrective measures. On the other hand, the surgeon doing a conventional repair with $\mathrm{CPB}$ would have to wait until the child is weaned from CPB before an accurate assessment of his repair with TEE can be obtained. In the case of any residual shunt, return to $\mathrm{CPB}$ is inevitable and time consuming. Many studies have pointed out the adverse effects of CPB in general and specifically on the development of the brain in children. ${ }^{17,18}$ More recent studies also documented that the perioperative mortality and morbidity can be improved if CPB is avoided. ${ }^{19}$ From this point of view, PVDC of VSDs not only can eliminate the side effects of CPB altogether if the child has no other associated CHDs, but can also markedly reduce the $\mathrm{CPB}$ time if the child does have other associated CHDs and also reduce the risk of postoperative residual shunt.

Our experience with the child (patient 6, Table 1) who had 2 small nearby MVSDs might have suggested that after the larger defect was closed with a device, the nearby smaller defect might become even smaller, making it difficult to pass the guidewire to the LV cavity to establish another pathway for the deployment of the second device. This might be due to the following: (1) the waist of the already inserted device might be compressing the muscle bridge between the 2 defects, thus effectively narrowing the diameter of the unclosed defect, and (2) the flanges of the in-site device might be partially covering up the nearby defect. If this occurs, it might be easier to close it with the aid of CPB, especially if there are other associated CHDs that require CPB for correction after an accurate assessment of the orientation of the residual defect with respect to the device has been established. The idea of using a bigger than necessary device to attempt to close 2 nearby small MVSDs is certainly tempting, and our experience with 2 cases has proved the feasibility. Our initial experience also suggested that PDA occluders can be effectively used to close apical MVSDs when the geography of the apex makes it difficult or impossible to deploy the regular bi-disc occluder.

In conclusion, PVDC appeared to be a safe, effective, and less invasive option for the treatment of either singular or multiple MVSDs, with or without associated CHDs. The results of the 6-month follow-up, in terms of stability of the devices, residual shunt, closure-related valve dysfunction, and new arrhythmia, are satisfactory. However, the conclusion derived from our experience is limited owing to the small size of the patients. Further studies with more patients and longer term follow-ups will be required to truly confirm the role of PVDC as an established form of treatment for MVSDs.

\section{References}

1. Alsoufi B, Karamlou T, Osaki M, Badiwala MV, Ching CC, Dipchand A, et al. Surgical repair of multiple muscular ventricular septal defects: the role of re-endocardialization strategy. J Thorac Cardiovasc Surg. 2006;132:1072-80.

2. Myhre U, Duncan BW, Mee RB, Joshi R, Seshadri SG, Herrera-Verdugo O, et al. Apical right ventriculotomy for closure of apical ventricular septal defects. Ann Thorac Surg. 2004;78:204-8. 
3. Van Praagh S, Mayer JE Jr, Berman NB, Flanagan MF, Geva T, Van Praagh R. Apical ventricular septal defects: follow-up concerning anatomic and surgical considerations. Ann Thorac Surg. 2002;73:48-56.

4. Hijazi ZM, Hakim F, Al-Fadley F, Abdelhamid J, Cao QL. Transcatheter closure of single muscular ventricular septal defects using the Amplatzer muscular VSD occluder: initial results and technical considerations. Cathet Cardiovasc Interv. 2000;49:167-72.

5. Holzer R, Balzer D, Cao QL, Lock K, Hijazi ZM. Device closure of muscular ventricular septal defects using the Amplatzer muscular ventricular septal defect occluder: immediate and mid-term results of a U.S. registry. J Am Coll Cardiol. 2004;43:1257-63.

6. Amin Z, Berry JM, Rocchini AL, Bass JL. Intraoperative closure of muscular ventricular septal defects in a canine model and application of the technique in a baby. J Thorac Cardiovasc Surg. 1998;115:1374-6.

7. Bacha EA, Cao QL, Starr JP, Waight D, Ebeid MR, Hijazi ZM. Perventricular device closure of muscular ventricular septal defects on the beating heart: technique and results. J Thorac Cardiovasc Surg. 2003;126:1718-23.

8. Zeng XJ, Sun SQ, Chen XF, Ma XJ, Luo YH, Lim YP, et al. Device closure of perimembranous ventricular septal defects with a minimally invasive technique in 12 patients. Ann Thorac Surg. 2008;85:192-4.

9. Gan CP, An Q, Lin K, Tang H, Lui RC, Tao KY, et al. Perventricular device closure of ventricular septal defects: 6 months results in 30 young children. Ann Thorac Surg. 2008;86:142-6.

10. Amin Z, Gu X, Berry JM, Bass JL, Titus JL, Urness M, et al. New device for closure of muscular ventricular septal defects in a canine model. Circulation. 1999; 100:320-8.
11. Pass RH, Hijazi Z, Hsu DT, Lewis V, Hellenbrand WE. Multicenter USA Amplatzer patent ductus arteriosus occlusion device trial: initial and one-year results. J Am Coll Cardiol. 2004;44:513-9.

12. Mavroudis C, Backer CL, Idriss FS. Ventricle septal defect. In: Mavroudis C Backer CL, eds. Pediatric cardiac surgery. 3rd ed. St Louis: Mosby; 2004: 201-24.

13. Houyel L, Vaksmann G, Fournier A, Davignon A. Ventricular arrhythmias after correction of ventricular septal defects: importance of surgical approach. $J$ Am Coll Cardiol. 1990;16:1224-8.

14. Seddio F, Reddy VM, McElhinney DB, Tworetzky W, Silverman NH, Hanley FL. Multiple ventricular septal defects: how and when should they be repaired? J Thorac Cardiovasc Surg. 1999;117:134-40.

15. Becker P, Frangini P, Heusser F, Urcelay G, Garay F. New surgical approach to device closure of multiple apical ventricular septal defects. Rev Esp Cardiol. 2004;57:1238-40.

16. Janorkar S, Goh T, Wilkinson J. Transcatheter closure of ventricular septal defects using the Rashkind device: initial experience. Catheter Cardiovasc Interv. 1999; 46:43-8.

17. Kern FH, Hickey PR. The effects of cardiopulmonary bypass on the brain. In Jonas RA, ed. Cardiopulmonary bypass in neonates, infants and young children. 1st ed. Boston: Blackwell Science; 1994:263-78.

18. Visconti KJ, Bichell DP, Jonas RA, Newburger JW, Bellinger DC. Developmental outcome after surgical versus interventional closure of secundum atrial septal defect in children. Circulation. 1999;100(suppl 19):II45-50.

19. Christian FS, Lara SS. Recent developments in the perioperative management of the paediatric cardiac patient. Curr Opin Anaesthesiol. 2006;19:375-81. 